\title{
Mesenchymal stem cells from patients with chronic myeloid leukemia do not express BCR-ABL and have absence of chimerism after allogeneic bone marrow transplant
}

R.C.V. Carrara,

M.D. Orellana, A.M. Fontes,

P.V.B. Palma, S. Kashima, M.R. Mendes, M.A. Coutinho, J.C. Voltarelli and D.T. Covas
Centro Regional de Hemoterapia, Departamento de Clínica Médica, Faculdade de Medicina de Ribeirão Preto, Universidade de São Paulo, Ribeirão Preto, SP, Brasil
Correspondence

D.T. Covas

Centro Regional de Hemoterapia FMRP, USP

Rua Tenente Catão Roxo, 2501

14051-140 Ribeirão Preto, SP

Brasil

Fax: +55-16-2101-9309

E-mail: dimas@fmrp.usp.br

Research supported by FAPESP (Nos. 1998/14247-6 and 01/07308-3).

$\ldots \ldots \ldots \ldots \ldots \ldots$

Received December 14, 2005 Accepted October 9, 2006

\section{Abstract}

Bone marrow is a heterogeneous cell population which includes hematopoietic and mesenchymal progenitor cells. Dysregulated hematopoiesis occurs in chronic myelogenous leukemia (CML), being caused at least in part by abnormalities in the hematopoietic progenitors. However, the role of mesenchymal stem cells (MSCs) in CML has not been well characterized. The objectives of the present study were to observe the biological characteristics of MSCs from CML patients and to determine if MSCs originate in part from donors in CML patients after bone marrow transplantation (BMT). We analyzed MSCs from 5 untreated patients and from 3 CML patients after sexmismatched allogeneic BMT. Flow cytometry analysis revealed the typical MSC phenotype and in vitro assays showed ability to differentiate into adipocytes and osteoblasts. Moreover, although some RTPCR data were contradictory, combined fluorescence in situ hybridization analysis showed that MSCs from CML patients do not express the $b c r$ - $a b l$ gene. Regarding MSCs of donor origin, although it is possible to detect $\mathrm{Y}$ target sequence by nested PCR, the low frequency $(0.14$ and $0.34 \%)$ of XY cells in 2 MSC CML patients by fluorescence in situ hybridization analysis suggests the presence of contaminant hematopoietic cells and the absence of host-derived MSCs in CML patients. Therefore, we conclude that MSCs from CML patients express the typical MSC phenotype, can differentiate into osteogenic and adipogenic lineages and do not express the $b c r-a b l$ gene. MSCs cannot be found in recipients 12 to 20 months after BMT. The influence of MSCs on the dysregulation of hematopoiesis in CML patients deserves further investigation.
Key words

- Mesenchymal stem cells - Chimerism

- Allogeneic hematopoietic stem cell transplantation

- Chronic myeloid leukemia

- bcr-abl gene 


\section{Introduction}

Bone marrow (BM) is composed of at least two systems, i.e., the hematopoietic tissue proper and the stroma $(1,2)$. Mesenchymal stem cells (MSCs) are important constituents of this microenvironment and are characterized as adult, non-hematopoietic stem cells (HSCs) which, after an adequate stimulus, can differentiate morphologically and functionally into different cell lines including the stroma, which gives support to hematopoiesis, adipocytes, chondrocytes, myocytes, astrocytes, tenocytes, and hepatocytes $(3,4)$.

In addition, studies by our group on the transcriptome of BM MSCs have shown both differences and similarities compared to $\mathrm{CD} 34^{+}$hematopoietic $\mathrm{BM}$ stem cells. About 1/3 of the most expressed gene products were present in both cell types, whereas 2/3 showed exclusive over-expression in one of the cell types (5).

Chronic myeloid leukemia (CML) is a myeloproliferative disease originating in multipotent HSCs which acquire the reciprocal translocation $\mathrm{t}(9 ; 22)(\mathrm{q} 34 ; \mathrm{q} 11)$ characterized cytogenetically by the presence of the Philadelphia (Ph1) chromosome. This translocation intercalates portions of the $c$ $a b l$ protooncogene in chromosome 9 with the $c$-bcr gene in chromosome 22, forming a hybrid $b c r$ - $a b l$ gene that codes for the BCRABL oncoprotein (6-8).

More recent studies have suggested a more primitive cellular origin for the $\mathrm{t}(9 ; 22)$ translocation $(9,10)$. Gunsilius et al. (9) identified the $b c r-a b l$ fusion gene in a more primitive progenitor cell $\left(\mathrm{CD} 34^{+} \mathrm{CD} 31^{+}\right)$than the hematopoietic cell which had the characteristics of a hemangioblast when isolated in vitro from the BM of patients with CML.

Fang et al. (10) isolated from the BM of patients with CML a population of even more primitive progenitor cells defined as Flk1 ${ }^{+}$ CD31- CD34- which also carried the $b c r-a b l$ fusion gene, and demonstrated in in vitro studies that, starting from cultures of a single cell, this population can give origin to both hematopoietic and endothelial cells, with both populations being malignant and able to produce CML when injected into SCID mice.

The objective of the present study was to determine the possible existence of the $b c r$ $a b l$ fusion gene in the MSCs of the BM of patients with CML. This would permit us to conclude the presence of this mutation in another more primitive progenitor cell population in addition to hemangioblasts. To this end, untreated MSCs were isolated from the $\mathrm{BM}$ of CML patients during the diagnostic phase and characterized phenotypically and cytogenetically.

In view of the controversial literature reports about the transplantation potential of MSCs (11-15), the degree of stromal microchimerism was evaluated in fractions of MSCs isolated from the BM of CML patients submitted to allogeneic bone marrow transplantation (BMT), in order to determine the migration and stromal reconstitution potential of donor MSCs in recipients submitted to the myeloablative conditioning regimen. This analysis was carried out by isolating MSCs obtained from 3 female patients who had received a BMT from a male donor, using nested PCR and fluorescence in situ hybridization (FISH).

\section{Patients, Material and Methods}

\section{Patients}

Twelve untreated CML patients were recently diagnosed $\mathrm{Ph}^{+}$in the chronic phase, and 3 were female patients with CML who had received an allogeneic BMT from male donors at the BMT service of the University Hospital, Faculty of Medicine of Ribeirão Preto. In order to investigate the biological characteristics of MSCs we isolated BM-MSC from 5 untreated patients. The other 7 untreated patients were used to obtain purified HSCs $\mathrm{CD}_{3} 4^{+}$from the $\mathrm{BM}$ and peripheral blood in order to identify and quantify the presence of the 9;22 $\left(\mathrm{Ph}^{+}\right)$translocation in 
these cell populations. We also analyzed the MSCs and hematopoietic cells of 3 female patients with CML after allogeneic BMT, and mononuclear cells from peripheral blood. The Ethics Committee of the Institution approved the study and all patients gave written informed consent to participate.

\section{Characteristics of the patients}

The clinical characteristics of the patients submitted to BMT are presented in Table 1. Mean patient age was 25.7 years (range: 24 to 29 years). The mean age of the untreated and non-transplanted CML patients was 37.4 years (range: 15 to 64 years). The cellularity of the BM of these untreated patients was $11-130 \times 10^{3} / \mathrm{mm}^{3}$ and the expression of the $b c r-a b l$ gene was demonstrated in all CML patients by RT-PCR (data not shown).

\section{Characteristics of the donors}

All donors were related to the recipients, i.e., HLA-identical brothers as determined by high-resolution molecular typing. One patient (CML 7) received peripheral blood mononuclear cells from a donor who was mobilized with G-CSF, $10 \mu \mathrm{g} / \mathrm{kg}$, sc, for 5 days and who had to be submitted to two leukopheresis procedures for the collection of mononuclear cells. The BM of the other donors was collected by multiple punctures of the posterior iliac bone under general anesthesia.

\section{Conditioning regimen for the patients}

All patients received a regimen of myeloablative conditioning with busulfan, $4 \mathrm{mg}$ $\mathrm{kg}^{-1}$ day $^{-1}$, for 4 days (days -7 to -4 ) and cyclophosphamide, $60 \mathrm{mg} \mathrm{kg}^{-1} \mathrm{day}^{-1}$, for 2 days (days -3 and -2 ).

\section{Prophylaxis against graft-versus-host disease}

Prophylaxis against graft-versus-host dis- ease was performed with cyclosporine and methotrexate (16). Cyclosporine was first administered intravenously, $3 \mathrm{mg} \mathrm{kg}^{-1}$ day $^{-1}$, by continuous infusion starting $24 \mathrm{~h}$ before $\mathrm{BM}$ or peripheral blood infusion. The dose was maintained until the occurrence of grafting and, as soon as the patient was able to swallow, cyclosporine was administered orally at the dose of $7.5 \mathrm{mg} \mathrm{kg}^{-1}$ day $^{-1}$ divided into two daily portions and the dose was then adjusted so as to keep a serum level between 200 and $400 \mathrm{ng} / \mathrm{mL}$. Methotrexate was administered intravenously at the dose of 15 $\mathrm{mg} / \mathrm{m}^{2}$ on day +1 and of $10 \mathrm{mg} / \mathrm{m}^{2}$ on days $+3,+6$, and +11 . The dose of methotrexate was adjusted on the basis of the presence of severe mucositis and renal or hepatic insufficiency according to the protocol of the institution.

\section{Isolation, culture and differentiation of mesenchymal stem cells}

BM samples from normal donors and from patients with CML were obtained from the iliac crest. The mononuclear cells were separated on a Ficoll-Paque ${ }^{\mathrm{TM}}$ Plus gradient (Amersham Biosciences, Uppsala, Sweden) and $2 \times 10^{7}$ mononuclear cells were cultured

Table 1. Characteristics of the patients, of the donors and of the allogeneic transplant in the present study.

\begin{tabular}{llll}
\hline Characteristics & CML 6 & CML 7 & CML 8 \\
\hline Patient's age/sex & 24/Female & 24/Female & 29/Female \\
Diagnosis & CML & CML & CML \\
Cytogenetics of patients & $46, \mathrm{XX}, \mathrm{t}(9 ; 22)$ & $46, \mathrm{XX}, \mathrm{t}(9 ; 22)$ & $46, \mathrm{XX}, \mathrm{t}(9 ; 22)$ \\
Phase of disease at BMT & $\mathrm{CP} 1$ & $\mathrm{CP} 1$ & $\mathrm{CP} 1$ \\
Conditioning regimen & $\mathrm{BU} / \mathrm{CY} 2$ & $\mathrm{BU} / \mathrm{CY} 2$ & $\mathrm{BU} / \mathrm{CY} 2$ \\
GVHD prophylaxis & $\mathrm{CSA} / \mathrm{MTX}$ & $\mathrm{CSA} / \mathrm{MTX}$ & $\mathrm{CSA} / \mathrm{MTX}$ \\
Donor's sex & Male & Male & Male \\
Donor's HLA type & Related/identical & Related/identical & Related/identical \\
WBC count transplanted & 3.6 & 2.4 & 3.7 \\
\multicolumn{1}{l}{ (x 108 cells/kg) } & & & \\
\hline
\end{tabular}

$\mathrm{BMT}$ = bone marrow transplant; $\mathrm{CML}=$ chronic myeloid leukemia; $\mathrm{CP} 1=$ chronic phase $1 ; \mathrm{BU} / \mathrm{CY} 2$ = busulfan, $16 \mathrm{mg} / \mathrm{kg}$, and cyclophosphamide, $120 \mathrm{mg} / \mathrm{kg} ; \mathrm{GVHD}=$ graft-versus-host disease; CSA $/$ MTX = cyclosporine, $3 \mathrm{mg} / \mathrm{kg} \mathrm{iv}$, and methotrexate, $15 \mathrm{mg} / \mathrm{m}^{2}$ on day +1 and $10 \mathrm{mg} / \mathrm{m}^{2}$ on days $+3,+6$ and +11 ; HLA = human leukocyte antigen; $\mathrm{WBC}=$ white blood cells. 
in $\alpha$-MEM (Invitrogen, Carlsbad, CA, USA) containing $15 \%$ fetal calf serum (Invitrogen) supplemented with $2 \mathrm{mM} \mathrm{L}$-glutamine, 100 $\mathrm{IU} / \mathrm{mL}$ penicillin and $100 \mathrm{mg} / \mathrm{mL}$ streptomycin. After 3-7 days, non-adherent cells were removed and adherent cells were maintained in culture and expanded with specific medium as previously described (5) after successive passages. After the third passage the cells were submitted to the adipogenic and osteogenic differentiation medium as previously described (17), and then separated for immunophenotyping, FISH and RT-PCR.

\section{Isolation and purification of CD34 ${ }^{+}$ hematopoietic stem cells}

Mononucleated BM and peripheral blood cells from 7 patients with CML were separated by Ficoll-Hypaque centrifugation (Histopaque $^{\circledR}-1077$, Sigma, St. Louis, MO, USA). $\mathrm{CD}^{+} 4^{+}$cells were obtained by positive selection using an immunomagnetic column to collect $\mathrm{CD} 34^{+}$cells coupled to microbeads according to the manufacturer's protocol (MACS, Milteny Biotec, Bergisch Gladbach, Germany). After selection, CD34+ $4^{+}$SCs were immediately labeled with anti-human phycoerythrinconjugated CD34 (Becton Dickinson, San Jose, CA, USA), anti-human FITC-conjugated CD14 (Becton Dickinson) or its isotypematched control (anti- $\gamma_{2 \mathrm{a}}$, Becton Dickinson) in PBS for $30 \mathrm{~min}$ at $4^{\circ} \mathrm{C}$ in the dark. After several washings, the cells were resuspended in $300 \mu \mathrm{L} \mathrm{2 \%} \mathrm{BSA/PBS} \mathrm{for} \mathrm{FACS} \mathrm{analysis.}$ Flow cytometry of 75,000 events was performed and analyzed with a FACSort (Becton Dickinson) running CellQuest data acquisition and analysis software (Becton Dickinson). CD $34^{+}$HSC populations presenting $\geq 90 \%$ purity were used in the present study.

\section{Mesenchymal stem cell separation and immunophenotyping}

The culture-expanded MSCs were imme- diately labeled with monoclonal antibodies specific for the following surface molecules: CD90-PE, CD73-PE, CD105-PE, CD51/61FITC, CD29-PE, CD49a-PE, CD49e-PE, CD49d-PE, CD49b-PE, CD54-PE, CD106PE, HLA-DR-FITC, HLA class I-FITC (Pharmingen, San Jose, CA, USA); CD13-PE, CD14-PE, CD34-PE, CD44-FITC, CD45FITC (Becton Dickinson); Ac133-PE(Milteny Biotec) or its isotype-matched control (anti$\gamma_{2 \mathrm{a}}$, Becton Dickinson) in PBS for $30 \mathrm{~min}$ at $4^{\circ} \mathrm{C}$ in the dark. After several washings, the cells were resuspended in $300 \mu \mathrm{L} \mathrm{2 \%} \mathrm{BSA/}$ PBS for FACS analysis. For KDR (SigmaAldrich) and STRO-1 (kindly provided by Dr. Bervely Torok-Storb - Fred Hutchinson Cancer Research Center, Seattle, WA, USA) staining, MSCs were incubated with a primary antibody at $4^{\circ} \mathrm{C}$ for $1 \mathrm{~h}$. Cells were washed twice with $2 \% \mathrm{BSA} / \mathrm{PBS}$ and incubated with a secondary antibody (goat anti-mouse IgG1 $(\gamma)$ FITC-conjugated antibody) for $1 \mathrm{~h}$ at $4^{\circ} \mathrm{C}$. After washing, cells were resuspended as mentioned above for FACS analysis. Flow cytometry analysis of 10,000 events was performed using a FACSort (Becton Dickinson) running CellQuest data aquisition and analysis software (Becton Dickinson). Forward scatter and light scatter were used for gating on staining cells and excluding cell debris.

In order to characterize MSCs from CML patients after BMT and to exclude contaminating hematopoietic cells we performed sorting with a FACS VANTAGE cytometer (Becton Dickinson). For this procedure, first culture-expanded MSCs were stained with anti-human CD90-FITC, CD54-PE, CD29PE, CD13-PE, CD14-PE and CD33-PE, or $\mathrm{PE}$ or FITC-conjugated isotype control (BD Biosciences, San Jose, CA, USA). After staining, cells were analyzed using the same cytometer apparatus. Sorting was then performed on the CD14-/CD33- cell population. These CD14-/CD33- MSCs were reanalyzed to determine the purity of the MSC population using the human monoclonal antibodies mentioned above. After sorting, in all 
experiments the $\mathrm{CD} 90^{+}$cell purity was $>96 \%$ and the presence of $\mathrm{CD} 14^{+} / \mathrm{CD} 33^{+}$contaminant cells was $<0.04 \%$. These purified cell populations were then analyzed by nested PCR for the SRY gene.

\section{Cytogenetic analysis}

To identify the presence of the Ph1 chromosome in patients with a diagnostic hypothesis of CML and to evaluate the degree of post-transplant hematopoietic chimerism during the different treatment phases, BM and peripheral blood samples were collected into heparinized tubes and analyzed by standard cytogenetic procedures. BM hematopoietic cells were processed by direct analysis, a method that does not require cell culture to obtain mitotic figures, with the metaphases obtained representing the in vivo situation of the cells at the time of sampling (18). Peripheral cell metaphases were obtained by temporary lymphocyte culture (19). The chromosomes were identified by G banding (trypsin-Giemsa) and 20 metaphases per sample were analyzed using the 1995 ISCN nomenclature (20).

\section{Fluorescence in situ hybridization}

The LSI BCR-ABL ES Dual Color probe (Vysis, Downer Grove, IL, USA) was used to identify the $b c r$ - $a b l$ fusion gene in the 5 MSC samples and in $7 \mathrm{CD} 34^{+} \mathrm{HSC}$ samples isolated from patients with $\mathrm{CML} \mathrm{Ph}^{+}$at diagnosis. The centromeric probes chromosome $\mathrm{X} \alpha$ satellite (DXZ1) and chromosome $\mathrm{Y} \alpha$ satellite (DXZ3) (Cytocell, Cambridge, UK) were used to quantify the chimerism of donor MSCs. The isolated MSC and HSC populations were treated with hypotonic solution $(0.075 \mathrm{mM} \mathrm{KCl})$ at $37^{\circ} \mathrm{C}$ for $20 \mathrm{~min}$, centrifuged at $200 \mathrm{~g}$ for 10 min and fixed with Carnoy solution (3:1 methanol:acetic acid; Merck, Darmstadt, Germany) for three cycles of 1-5 min followed by centrifugation at $200 \mathrm{~g}$ for $10 \mathrm{~min}$. The nucleus suspension was fixed and placed on slides and the preparations of best quality were selected by phase microscopy. The selected slides were pretreated with a $2 \mathrm{X}$ sodium chloride and sodium citrate solution, $\mathrm{pH} 7.0$, at $37^{\circ} \mathrm{C}$ for 10 min, dehydrated in an increasing ethanol series (Merck) (70, 85, and 100\%) for 5 min each and air dried. Nuclear DNA was denatured and hybridized according to the protocol provided by the manufacturer of the Vysis probes, followed by counterstaining with 10 $\mu \mathrm{L}$ of DAPI-II antifade solution (Vysis). In each case, at least 200 isolated nuclei were examined for the presence of the $b c r-a b l$ genes and about 600 nuclei were studied for XX/XY chimerism. The images were acquired with an AxioCam digital camera and analyzed with the AxioVision 3.0 software (Carl Zeiss, Oberkochen, Germany) using the Axioskop2 fluorescence microscope (Carl Zeiss) with the DAPI, FITC and rhodamine filters.

RT-PCR analysis of the bcr-abl gene in the mesenchymal stem cells of patients with chronic myelogenous leukemia

Total MSC RNA was extracted with Trizol ${ }^{\circledR}$ LS (Gibco BRL ${ }^{\circledR}$, Grand Island, NY, USA). Reverse transcription was performed using the specific primer 2OABL1: 5' TGA TTA AGC CTA AGA CCC GGA 3' and the reverse transcription kit SuperScript III (Invitrogen). The fusion gene $b c r-a b l$ was amplified by nested PCR using the synthetic MBCR1 oligonucleotides 5' GAA GTG TTT CAG AAG CTT CTC C 3' and mBCR1 5' CCA TCG TGG GCG TCC GCA 3 ' in a first amplification reaction with 26 cycles of $30 \mathrm{~s}$ at $94^{\circ} \mathrm{C}, 40 \mathrm{~s}$ at $51^{\circ} \mathrm{C}$ and $1 \mathrm{~min}$ at $72^{\circ} \mathrm{C}$. The MBCR2 oligonucleotides 5' TGG AGC TGC AGA TGC TGA CCA ACT C 3' and Mbcr2 5'AGA TCT GGC CCA ACG ATG GCG AGG GC $3^{\prime}$ were used in a second reaction of 35 cycles of $30 \mathrm{~s}$ at $94^{\circ} \mathrm{C}, 40 \mathrm{~s}$ at $60^{\circ} \mathrm{C}$ and $1 \mathrm{~min}$ at $72^{\circ} \mathrm{C}$. A final 10 -min extension at $72^{\circ} \mathrm{C}$ was performed in both reactions, which were carried out together with the amplification of the $\mathrm{ABL}$ gene for internal control 
using the 2OABL1 oligonucleotides 5' TGA TTA AGC CTA AGA CCC GGA 3' and LICABL2: 5'ACT GAA GCC GCT CGT TGG AAC TCC 3'. In these PCR assays, 2.5 $\mu \mathrm{M}$ of each oligonucleotide, $2 \mathrm{mM}$ dNTPs and 1 unit of Taq polymerase were used in a final volume of $25 \mu \mathrm{L}$.

\section{Analysis of donor chimerism by nested PCR}

MSC DNA was extracted by digestion with proteinase $\mathrm{K}$ starting from 1 x $10^{5}$ cells.
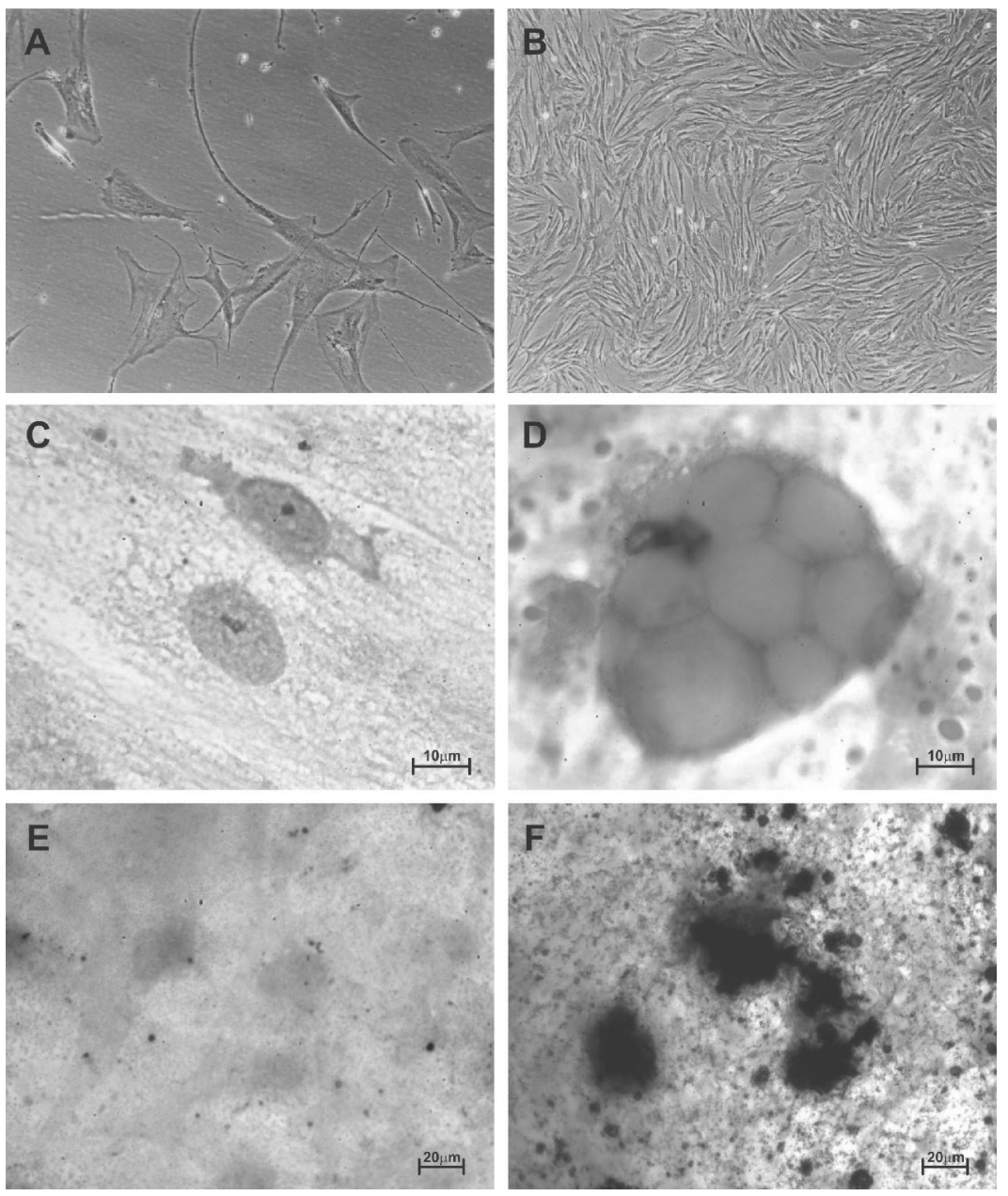

Figure 1. Morphology of bone marrow-mesenchymal stem cells (BM-MSCs) in culture, BMMSCs without differentiation induction and after differentiation into adipocyte and osteocyte from an untreated chronic myeloid leukemia (CML) patient. $A$, Photomicrography of the culture of MSCs isolated from the BM where it is observed a fibroblastic morphology with $25 \%$ confluence (magnitude order X100), and B, with $100 \%$ confluence (magnitude order $X 40)$. $D$ and $F$ show BM-MSC differentiated into adipocyte and osteocyte after staining with Sudan II-Scarlet and Harris hematoxylin or Von Kossa, respectively. $C$ and $E$ represent their respective controls (BM-MSCs without induction of medium differentiation).
Briefly, the cell pellet was digested in 40 to 50 $\mu \mathrm{L}$ lysis buffer $(100 \mathrm{mM} \mathrm{NaCl}, 10 \mathrm{mM}$ Tris $\mathrm{HCl}, \mathrm{pH} 8.0,25 \mathrm{mM}$ EDTA, pH 8.0, 0.5\% $\mathrm{SDS}$, and $0.1 \mathrm{mg} / \mathrm{mL}$ proteinase $\mathrm{K}$ ) and incubated for $2 \mathrm{~h}$ at $55^{\circ} \mathrm{C}$. After digestion, the enzyme was inactivated by incubation at $95^{\circ} \mathrm{C}$ for $8 \mathrm{~min}$. Approximately 2 to $5 \mu \mathrm{L}$ of the digestion mixture was submitted to nested PCR. Two PCR cycles with two distinct sets of synthetic oligonucleotides were performed in this procedure. Both reactions consisted of 35 cycles of $30 \mathrm{~s}$ at $94^{\circ} \mathrm{C}, 40 \mathrm{~s}$ at a specific annealing temperature and $40 \mathrm{~s}$ at $72^{\circ} \mathrm{C}$. After each cycle, a final 10 -min extension at $72^{\circ} \mathrm{C}$ was performed. The oligonucleotides for the SRY gene were: a) for the first reaction 5'GAATATTCCCGCTCTCCGGA-3' and 5' GTACAACCTGTTGTCCAGTTG-3' at an annealing temperature of $57^{\circ} \mathrm{C}$, resulting in a PCR product of $416 \mathrm{bp}$, and $\mathrm{b}$ ) for the second reaction 5'-CAGTGTGAAACGGGAGAA AACAGT-3' and 5'-GACGAGGTCGATACT TATAATTCG-3' at an annealing temperature of $60^{\circ} \mathrm{C}$, resulting in a $\mathrm{PCR}$ product of $264 \mathrm{bp}$. As a control, the $\beta$-globin gene was amplified by nested PCR using the primers 5'-CGTAAA TACACTTGCAAAGGAG-3' and 5'-CAG AGAGAGTCAGTGCCTATC-3', resulting in a 510-bp product after the first reaction, and the oligonucleotides 5'-GAAGAGCCAAGG ACAGGTAC-3' and 5'-CAACTTCATCCA CGTTCACC-3', resulting in a PCR product of $267 \mathrm{bp}$ after the second reaction. For this gene, the annealing temperature was $57^{\circ} \mathrm{C}$ in both reactions. In these PCR assays, 40 pmol of each oligonucleotide, $0.2 \mathrm{mM}$ dNTPs and 2 Taq polymerase units were used in a final volume of $25 \mu \mathrm{L}$.

\section{Results}

Isolation, phenotypic analysis and potential for differentiation of the mesenchymal stem cells from the bone marrow of individuals with chronic myelogenous leukemia

The MSC populations of the BM from 5 
untreated patients in the chronic phase of CML, 3 female patients with CML who had received a BMT from a male donor, and 3 normal individuals were isolated, expanded and immunophenotyped. All samples permitted the isolation (based on the ability to adhere to plastic), culture and expansion of MSCs. The MSCs isolated from normal individuals permitted the expansion of at least 20 passages, while the MSCs isolated from patients with CML demonstrated a considerable reduction of their capacity for ex vivo expansion, which was limited between the 5th and 6th passages. In the 3rd passage, the MSCs obtained from CML patients at diagnosis and after transplantation presented typical fibroblastoid morphological characteristics with a capacity for differentiation similar to that of normal MSCs. Figure 1 illustrates the morphology of cultured MSCs from an untreated patient with CML (Figure $1 \mathrm{~A}$ and $\mathrm{B}$ ) and the morphology of these cultured cells without adipogenic (Figure 1C) and osteogenic medium (Figure 1E) or after differentiation into adipocytes and osteocytes (Figure 1D and F).

All MSC samples were submitted to immunophenotyping between the second and fourth passage and were found to express CD105, CD73 (SH3/SH4), CD90, CD29, CD13, HLA ABC, CD49e, CD44, Stro-1, CD49a, CD49b, CD54, and CD106 antigens, but they did not express hematopoietic markers (CD34, CD14, CD45, and CD133) or endothelial markers (KDR) and HLA-DR (Table 2). Our data show that in untreated CML patients the expression pattern for most of these MSC CD markers was similar to that found in normal samples. However, a slight difference was found for some surface antigens such as CD105, HLA ABC, CD49e, and CD44. The fact that MSCs comprise a heterogeneous population containing sub-populations at different stages of differentiation or small variations in antibody specificity when different lots are used can explain these differences in gene expression pattern.
BCR-ABL is not detected in mesenchymal stem cells isolated from the bone marrow of patients with chronic myelogenous leukemia

Primary cultures of adherent MSCs from the BM of 5 untreated patients with CML were evaluated in an attempt to identify the presence of the 9;22 translocation in these cells of the stromal microenvironment. Table 3 shows the results obtained by FISH for the MSC samples from the 5 untreated CML cases and from 1 control case. In two of these samples, CML 1 and CML 2, one BCR-ABL ${ }^{+}$nucleus was detected among approximately 180 nuclei analyzed. These results could not be confirmed by RT-PCR

Table 2. Immunophenotypic characteristics of mesenchymal stem cells obtained from the bone marrow (BM) of normal donors and untreated patients with chronic myeloid leukemia (CML).

\begin{tabular}{lcc}
\hline & $\begin{array}{c}\text { Normal BM } \\
\text { (mean \%) }\end{array}$ & $\begin{array}{c}\text { CML BM } \\
\text { (mean \%) }\end{array}$ \\
\hline CD105 & $81.53 \%$ & $38.70 \%$ \\
CD73 (SH3/SH4) & $88.35 \%$ & $81.81 \%$ \\
Stro-1 & $19.57 \%$ & $13.61 \%$ \\
CD90 (Thy-1) & $98.65 \%$ & $83.46 \%$ \\
CD29 (b1-integrin) & $94.05 \%$ & $93.77 \%$ \\
CD13 & $88.38 \%$ & $96.30 \%$ \\
HLA ABC & $86.69 \%$ & $74.97 \%$ \\
CD49a (VLA-1) & $12.67 \%$ & $19.81 \%$ \\
CD49b (VLA-2) & $20.65 \%$ & $36.53 \%$ \\
CD49e (VLA-5) & $97.42 \%$ & $68.63 \%$ \\
CD54 (ICAM-1) & $27.04 \%$ & $21.42 \%$ \\
CD44 & $89.00 \%$ & $58.39 \%$ \\
CD106 (VCAM-1) & $15.34 \%$ & $18.70 \%$ \\
CD34 & $1.67 \%$ & $0.33 \%$ \\
CD14 & $0.44 \%$ & $0.07 \%$ \\
CD45 & $0.09 \%$ & $0.13 \%$ \\
AC133 & ND & $0.02 \%$ \\
HLA-DR & $2.55 \%$ & $0.70 \%$ \\
KDR (VEGFR-2) & $9.34 \%$ & $1.12 \%$ \\
\hline
\end{tabular}

These results correspond to the percent of positive cells for each antigen marker in all cell populations. These analyses were performed for three samples except for the CD105 marker of the CML sample, where only one sample was labeled. ND = not done; HLA = human leukocyte antigen; VLA = very late action; ICAM = intercellular adhesion molecule; VCAM-1 = vascular cell adhesion molecule-1; VEGFR-2 = vascular endothelial growth factor receptor-2. 
Figure 2. Fluorescence in situ hybridization (FISH) of the mesenchymal stem cells (MSCs) and hematopoietic stem cells (HSCs) of patients with chronic myeloid leukemia (CML). A, IFISH BCR-ABL using the LSI BCR-ABL ES Dual Color probe (Vysis) in the MSCs of the CML 1 patient showing two negative BCR-ABL cells $\left(\mathrm{Ph}^{-}\right)$and one positive cell $\left(\mathrm{Ph}^{+}\right)$(1000X). B Analysis of the bcr-abl fusion gene by I-FISH in the CD34+ HSCs purified from the bone marrow (BM) of a patient with CML Ph1+, without treatment, showing the presence of one normal nucleus $\left(\mathrm{Ph}^{-}\right)$and a nucleus with $\mathrm{t}(9 ; 22)\left(\mathrm{Ph}^{+}\right)$, demonstrating the biclonal origin of CML in the HSCs (1000X). ES = extra signal. $C$, I-FISH using centromeric probes for the chromosome $\mathrm{X} \alpha$ satellite (DXZ1) and $Y \alpha$ satellite (DXZ3; Cytocell) in the positive MSC XY isolated from a female patient after allogeneic transplantation of BM from a male donor (1000X), and $D$, in the positive MSC XX (1000X).
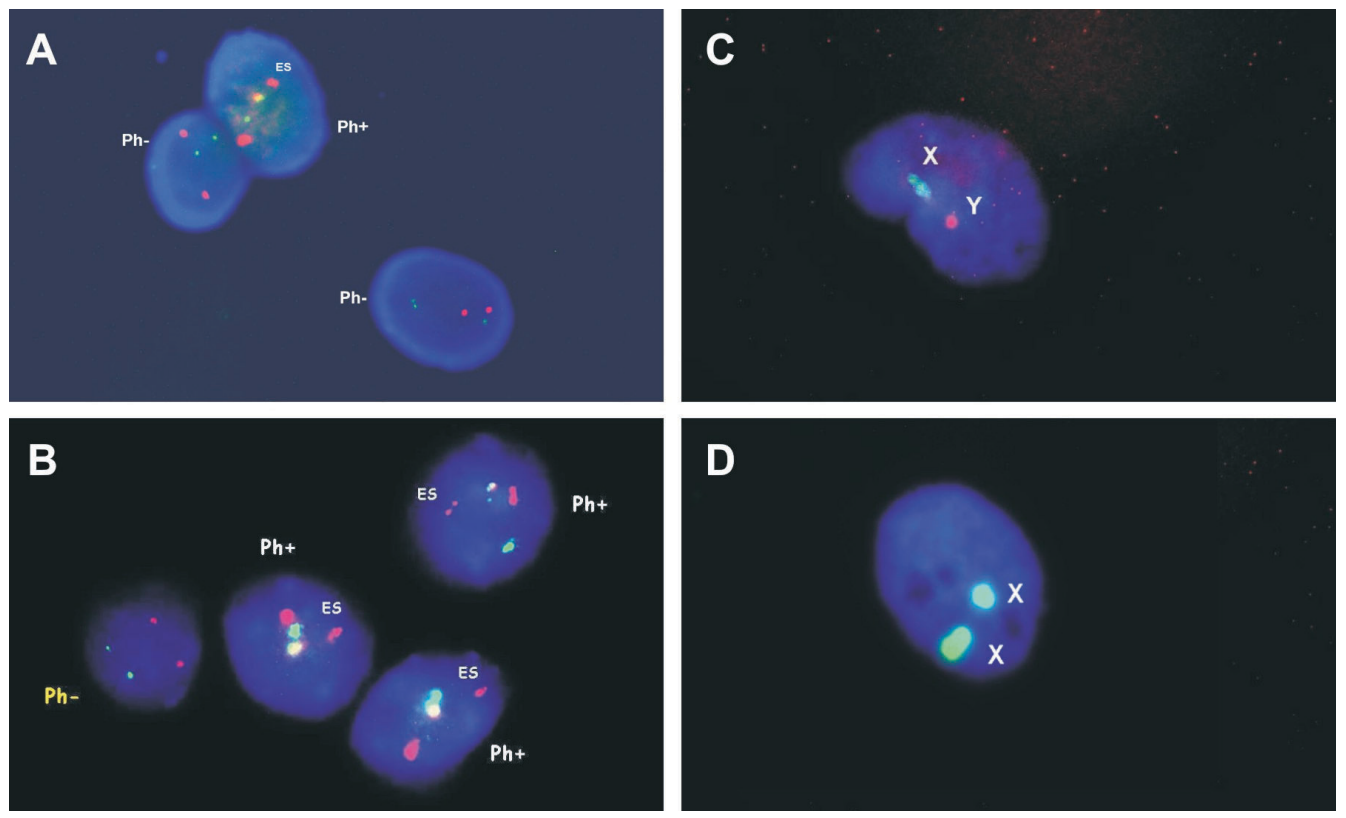

Table 3. Fluorescence in situ hybridization (FISH) analysis of the bcr-abl fusion gene in the mesenchymal stem cells isolated from the bone marrow of individuals with chronic myeloid leukemia (CML).

\begin{tabular}{lcccc}
\hline Case & $\begin{array}{c}\text { Passage No. } \\
\text { (cytometry/FISH/RT-PCR) }\end{array}$ & $\begin{array}{c}\text { No. of nuclei } \\
\text { analyzed }\end{array}$ & $\begin{array}{c}\text { No. of BCR-ABL- } \\
\text { nuclei }(\%)\end{array}$ & $\begin{array}{c}\text { No. of BCR-ABL+ } \\
\text { nuclei }(\%)\end{array}$ \\
\hline CML 1 & $4 \% 4^{\circ} / 5^{\circ}$ & 195 & $194(99.5 \%)$ & $1(0.5 \%)$ \\
CML 2 & $4 \% / 5^{\circ}$ & 174 & $173(99.5 \%)$ & $1(0.5 \%)$ \\
CML 3 & $2 \% \%$ - & 400 & $400(100 \%)$ & 0 \\
CML 4 & $2 \% / 3 \%$ & 295 & $295(100 \%)$ & 0 \\
CML 5 & $2 \% / 3 \%$ & 451 & $451(100 \%)$ & 0 \\
Normal & $2 \% / 3 \%$ & 211 & $211(100 \%)$ & 0 \\
\hline
\end{tabular}

Table 4. Analysis of $X / Y$ chimerism by nested polymerase chain reaction (PCR) and fluorescence in situ hybridization (FISH) X/Y after bone marrow transplantation (BMT).

\begin{tabular}{|c|c|c|c|c|c|c|c|c|}
\hline \multirow{4}{*}{$\begin{array}{l}\text { Case } \\
\text { post-BMT }\end{array}$} & \multirow{4}{*}{$\begin{array}{c}\text { Age } \\
\text { (years) }\end{array}$} & \multirow{4}{*}{$\begin{array}{c}\text { Time } \\
\text { post-BMT } \\
\text { (days) }\end{array}$} & \multirow{4}{*}{$\begin{array}{c}\text { BM } \\
\text { karyotype }\end{array}$} & \multicolumn{4}{|c|}{ Nested PCR SRY } & \multirow{4}{*}{$\begin{array}{c}\text { FISH X/Y } \\
\text { MSCs } \\
\text { (post-sorting) }\end{array}$} \\
\hline & & & & Post- & t-sorting & & & \\
\hline & & & & \multicolumn{2}{|c|}{$\begin{array}{l}\text { MSCs (CD90 }+/ \mathrm{MSCs}_{\left(\mathrm{CD} 90^{-} /\right.} \\
\left.\left.\mathrm{CD}^{-} 3^{-} / \mathrm{CD} 14^{-}\right) \mathrm{CD}^{+} / \mathrm{CD}^{+} 4^{+}\right)\end{array}$} & \multirow[t]{2}{*}{$\begin{array}{l}\text { MNC } \\
\text { BM }\end{array}$} & \multirow[t]{2}{*}{$\begin{array}{c}\text { MNC } \\
\text { PB }\end{array}$} & \\
\hline & & & & $\mathrm{BM}$ & $\mathrm{BM}$ & & & \\
\hline CML 6 & 24 & 551 & $94 \% 46, X Y$ & + & + & + & + & $0.3 \% X Y(2 / 654)$ \\
\hline CML 7 & 24 & 575 & $68 \% 46, X Y$ & + & + & ND & + & $0.1 \% X Y(1 / 701)$ \\
\hline CML 8 & 29 & 359 & $100 \% 46, X Y$ & - & + & ND & + & - \\
\hline
\end{tabular}

$\mathrm{ND}=$ Not done. The bone marrow karyotype corresponds to the percent of hematopoietic metaphases of the donor $(46, \mathrm{XY})$ detected in the recipient in a total of 50 cells analyzed by classic cytogenetics. $\mathrm{BM}=$ bone marrow; $\mathrm{MSC}=$ mesenchymal stem cells; $\mathrm{MNC}=$ mononuclear cells; $\mathrm{PB}=$ peripheral blood; $\mathrm{CML}=$ chronic myeloid leukemia. 
in the two samples cited above. Curiously, the data for the CML 1 samples were not reproducible in the three reactions, with positivity for the $b c r-a b l$ gene being diagnosed in only two of the three reactions performed. In contrast, in the CML 2 sample negativity was confirmed in all three reactions. The possibility of a false-positive result of FISH is very low since the probe used (LSI BCRABL ES Dual Color-Vysis) is characterized by giving origin to an extra signal coming from the ASS gene (synthetase argininosuccinate) located on the long arm of chromosome $9(9 q)$, the derivative of $t(9 ; 22)$, in addition to the signal of $b c r$ - $a b l$ fusion, thus increasing the reliability of our results. The fact that the second sample was negative in RT-PCR suggests the presence of a cell contaminant of hematopoietic origin detected in the samples analyzed by FISH.

As a control, highly purified CD $34^{+} \mathrm{HSCs}$ of $\mathrm{BM}$ and of peripheral blood from untreated patients with CML were analyzed by FISH in order to quantify the presence of the fusion gene $b c r-a b l$ in this cell population (Figure 2). The present results show that the number of $b c r$-abl-positive CD34+ $\mathrm{HSCs}$ ranged from 92 and $100 \%$ in $\mathrm{BM}$ and from 94 to $99 \%$ in purified peripheral blood samples. This analysis was also performed in mononuclear cell populations isolated from the $\mathrm{BM}$ and peripheral blood of a patient with CML, revealing that approximately $92 \%$ of the mononuclear cells of BM and $95 \%$ of those of peripheral blood were $b c r-a b l$ positive (data not shown).

\section{Absence of chimerism in the bone marrow of patients after bone marrow transplantation}

$\mathrm{XX} / \mathrm{YY}$ stromal chimerism was quantified by FISH using centromeric probes for chromosomes X and Y (Figure 2). The analysis was performed on 2 MSC samples that were found to be SRY positive by nested PCR. The percentage of XY MSCs was $0.3 \%$ $(2 / 654)$ in one of the $\mathrm{SRY}^{+}$sample (CML 6) and $0.1 \%$ in the other (1/701; CML 7). All mononuclear cell samples from BM and peripheral blood evaluated by nested PCR were $\mathrm{SRY}^{+}$, as also were the contaminating monocytes $\left(\mathrm{CD} 14^{+}\right.$cells) isolated from the MSC population by flow cytometry (Table 4 ). As suggested in the analysis of the $b c r-a b l$ gene in the MSCs of CML patients, we believe that the small percentage of positive $\mathrm{XY}$ nuclei observed in the present study (3/1355 $=0.02 \%$ ) was due to the presence of contaminating hematopoietic cells. As a control, we evaluated the mononuclear cells of the peripheral blood and BM of these patients by nested PCR and confirmed the presence of chromosome $\mathrm{Y}$ in all samples (Table 4). To determine the kinetics of engraftment of donor cells in the hematopoietic tissue, a retrospective chromosome analysis of BM samples from the recipients was performed during different phases after BMT. The results indicated that the largest percentage of hematopoietic metaphases analyzed were from the donor (68 to $100 \%$ $46, \mathrm{XY})$ at the time of sample collection (Table 4).

\section{Discussion}

We determined the presence of the $b c r$ $a b l$ gene in the MSCs of BM from CML patients in order to determine the role of MSCs in the genesis of CML. We then investigated whether this mutation might occur in a more primitive progenitor cell population common to MSCs and HSCs, as observed for endothelial cells of patients with CML $(9,10)$. To this end, we characterized phenotypically and cytogenetically a population of MSCs isolated from the BM of 5 $\mathrm{Ph}^{+}$-untreated CML patients. Analysis of the $b c r$-abl gene by FISH in 1513 nuclei detected $0.01 \%(2 / 1513)$ bcr-abl-positive MSCs. Since the MSCs analyzed were obtained from only a few starting colonies, giving origin to a clonal cell population, the detection of two $b c r$-abl-positive nuclei sug- 
gests the presence of hematopoietic contaminants in the culture of these cells, possibly $\left(\mathrm{CD} 14^{+}\right)$bcr-abl-positive macrophages that grow adhering to MSCs. Bhatia et al. (1) also described contaminating $b c r$-abl-positive macrophages in in vitro cultures of stromal cells from the BM of CML patients and suggested that the abnormal function of the stroma in CML may be due to the presence of $b c r$-abl-positive macrophages detected in the marrow microenvironment that may contribute to the selective expansion of leukemic HSCs. The immunophenotypic analysis of MSCs from CML patients did not show any significant difference compared to MSCs isolated from normal individuals. Our results agree with data reported by Zhao et al. (21) in an article that was published during the preparation of the present manuscript. The authors reported that MSCs in CML patients express the typical MSC CD markers, but they did not show the percentage of positive cells for each surface antigen in comparison with normal BM-MSCs.

Several in vivo studies on animal models have demonstrated that MSCs can migrate and differentiate into various tissues after allogeneic transplants (22-25). However, the transplantability of MSCs in humans is still controversial. Some studies investigating the degree of MSC chimerism in patients submitted to allogeneic BMT from donors of the opposite sex have demonstrated that some MSCs can be from the donor $(13,14,26)$, whereas others did not report this finding (11, 12,15). In the present study, we observed the absence of transplantability of the MSCs isolated from 3 patients with CML submitted to allogeneic transplantation with a myeloablative conditioning regimen. In these analyses we demonstrated the absence of donor MSCs in the stroma of the recipient, suggesting that the type of conditioning used does not seem to damage the stromal microenvironment, a fact that did not provide the engraftment of donor MSCs during the study period (between +359 and +575 days).
Although 2 of the 3 patients analyzed presented 0.1 and $0.3 \%$ microchimerism, we believe that the $\mathrm{SRY}^{+} / \mathrm{XY}^{+}$cells respectively detected by nested PCR and FISH were hematopoietic contaminants which still persisted in small amounts in these samples. Thus, the present study supports previous investigations that did not demonstrate stromal microchimerism after allogeneic BMT. These results suggest that the type of standard conditioning used (busulfan + cyclophosphamide) does not seem to influence the origin of MSCs after transplantation, although we cannot exclude the possibility of detecting stromal microchimerism in patients submitted to other conditioning regimens during more recent post-BMT periods and/or in other hematologic diseases, as described by Villaron et al. $(14,27)$. These investigators detected partial chimerism in the MSCs of the donor (26.13 and $60.17 \%)$ in 2 patients with multiple myeloma after BMT with a conditioning regimen of reduced intensity (fludarabine + melphalan). However, it should be pointed out that multiple myeloma can damage the stromal microenvironment, possibly explaining the chimerism observed by Villaron et al. (14) in patients with the disease. Taken together, these data agree with a recent study by Polony et al. (28) which demonstrated the transplantability of MSC in 8 of 26 patients analyzed. None of them were CML patients and 2 of them were MM patients.

Therefore, we conclude that MSCs from CML patients express the typical MSC phenotype, can be differentiated into osteogenic and adipogenic lineages and do not express the bcr-abl gene. However, the influence of MSCs on the dysregulation of hematopoiesis in CML patients is worthy of further investigation. Moreover, MSCs from healthy donors cannot be found in recipients 12 to 20 months after allogeneic BMT.

\section{Acknowledgments}

We are grateful to the patients who par- 
ticipated in this study. We are also very

Lopes Silva and Valéria Mendes Motta for

grateful to Amélia Góes Araújo, Ane Rose

technical support.

\section{References}

1. Bhatia R, McGlave PB, Dewald GW, Blazar BR, Verfaillie CM. Abnormal function of the bone marrow microenvironment in chronic myelogenous leukemia: role of malignant stromal macrophages. Blood 1995; 85: 3636-3645.

2. Prockop DJ. Marrow stromal cells as stem cells for nonhematopoietic tissues. Science 1997; 276: 71-74.

3. Caplan AI, Bruder SP. Mesenchymal stem cells: building blocks for molecular medicine in the 21st century. Trends Mol Med 2001; 7 : 259-264.

4. Minguell JJ, Erices A, Conget P. Mesenchymal stem cells. Exp Biol Med 2001; 226: 507-520.

5. Silva WA Jr, Covas DT, Panepucci RA, Proto-Siqueira R, Siufi JL, Zanette DL, et al. The profile of gene expression of human marrow mesenchymal stem cells. Stem Cells 2003; 21: 661-669.

6. Nowell PC, Hungerford DA. A minute chromosome in human chronic granulocytic leukemia. Science 1960; 132: 1497 (Abstract).

7. Kabarowski JH, Witte ON. Consequences of BCR-ABL expression within the hematopoietic stem cell in chronic myeloid leukemia. Stem Cells 2000; 18: 399-408.

8. Deininger MW, Goldman JM, Melo JV. The molecular biology of chronic myeloid leukemia. Blood 2000; 96: 3343-3356.

9. Gunsilius E, Duba HC, Petzer AL, Kahler CM, Grunewald K, Stockhammer G, et al. Evidence from a leukaemia model for maintenance of vascular endothelium by bone-marrow-derived endothelial cells. Lancet 2000; 355: 1688-1691.

10. Fang B, Zheng C, Liao L, Han Q, Sun Z, Jiang X, et al. Identification of human chronic myelogenous leukemia progenitor cells with hemangioblastic characteristics. Blood 2005; 105: 2733-2740.

11. Awaya N, Rupert K, Bryant E, Torok-Storb B. Failure of adult marrow-derived stem cells to generate marrow stroma after successful hematopoietic stem cell transplantation. Exp Hematol 2002; 30: 937-942.

12. Stute N, Fehse B, Schroder J, Arps S, Adamietz P, Held KR, et al. Human mesenchymal stem cells are not of donor origin in patients with severe aplastic anemia who underwent sex-mismatched allogeneic bone marrow transplant. J Hematother Stem Cell Res 2002; 11: $977-984$.

13. Cilloni D, Carlo-Stella C, Falzetti F, Sammarelli G, Regazzi E, Colla $S$, et al. Limited engraftment capacity of bone marrow-derived mesenchymal cells following T-cell-depleted hematopoietic stem cell transplantation. Blood 2000; 96: 3637-3643.

14. Villaron EM, Almeida J, Lopez-Holgado N, Alcoceba M, SanchezAbarca LI, Sanchez-Guijo FM, et al. Mesenchymal stem cells are present in peripheral blood and can engraft after allogeneic hematopoietic stem cell transplantation. Haematologica 2004; 89: 14211427.

15. Rieger K, Marinets O, Fietz T, Korper S, Sommer D, Mucke C, et al. Mesenchymal stem cells remain of host origin even a long time after allogeneic peripheral blood stem cell or bone marrow transplanta- tion. Exp Hematol 2005; 33: 605-611.

16. Storb R, Deeg HJ, Pepe M, Doney K, Appelbaum F, Beatty P, et al. Graft-versus-host disease prevention by methotrexate combined with cyclosporin compared to methotrexate alone in patients given marrow grafts for severe aplastic anaemia: long-term follow-up of a controlled trial. Br J Haematol 1989; 72: 567-572.

17. Covas DT, Siufi JL, Silva AR, Orellana MD. Isolation and culture of umbilical vein mesenchymal stem cells. Braz J Med Biol Res 2003; 36: 1179-1183.

18. Coutinho V, Bottura C. Método direto para o estudo dos cromossomos humanos. Rev Paul Med 1968; 72: 9-13.

19. Moorhead PS, Nowell PC, Mellman WJ, Battips DM, Hungerford DA. Chromosome preparations of leukocytes cultured from human peripheral blood. Exp Cell Res 1960; 20: 613-616.

20. Mitelman F. ISCN 1995: An international system for human cytogenetic nomenclature. Switzerland: S. Karger AG/Cytogenetics and Cell Genetics; 1995.

21. Zhao Z, Tang X, You Y, Li W, Liu F, Zou P. Assessment of bone marrow mesenchymal stem cell biological characteristics and support hematopoiesis function in patients with chronic myeloid leukemia. Leuk Res 2006; 30: 993-1003.

22. Hayakawa J, Migita M, Ueda T, Shimada T, Fukunaga Y. Generation of a chimeric mouse reconstituted with green fluorescent protein-positive bone marrow cells: a useful model for studying the behavior of bone marrow cells in regeneration in vivo. Int $\mathrm{J}$ Hematol 2003; 77: 456-462.

23. Devine SM, Cobbs C, Jennings M, Bartholomew A, Hoffman R. Mesenchymal stem cells distribute to a wide range of tissues following systemic infusion into nonhuman primates. Blood 2003; 101: 2999-3001.

24. Chapel A, Bertho JM, Bensidhoum M, Fouillard L, Young RG, Frick $\mathrm{J}$, et al. Mesenchymal stem cells home to injured tissues when coinfused with hematopoietic cells to treat a radiation-induced multiorgan failure syndrome. J Gene Med 2003; 5: 1028-1038.

25. Mahmud N, Pang W, Cobbs C, Alur P, Borneman J, Dodds R, et al. Studies of the route of administration and role of conditioning with radiation on unrelated allogeneic mismatched mesenchymal stem cell engraftment in a nonhuman primate model. Exp Hematol 2004; 32: 494-501.

26. Keating A, Singer JW, Killen PD, Striker GE, Salo AC, Sanders J, et al. Donor origin of the in vitro haematopoietic microenvironment after marrow transplantation in man. Nature 1982; 298: 280-283.

27. Villaron EM, Perez-Simon JA, San Miguel JF, del Canizo C. Bone marrow mesenchymal stem cells chimerism after allogeneic hematopoietic transplantation. Exp Hematol 2006; 34: 7.

28. Poloni A, Leoni P, Buscemi L, Balducci F, Pasquini R, Masia MC, et al. Engraftment capacity of mesenchymal cells following hematopoietic stem cell transplantation in patients receiving reduced-intensity conditioning regimen. Leukemia 2006; 20: 329-335. 